\title{
ТЕРМИНОЛОГИЯ В ПРОМЫШЛЕННОЙ АРХИТЕКТУРЕ: СТАНОВЛЕНИЕ И РАЗВИТИЕ
}

\section{Е. Б. Морозова ${ }^{1}$}

${ }^{1}$ Доктор архитектуры, профессор, зав. кафредрой «Архитектура производственных объектов и архитектурные конструкции» учреждения образования «Белорусский национальный технический университет», Минск, Беларусь, email: emorozova@bntu.by

\section{Ресрерат}

Система терминов и понятий составляет необходимый научно-практической аппарат в любой сфере деятельности, в том числе в промышленной архитектуре. Роль терминологии в условиях глобализации процессов и явлений современного мира сегодня значительно усиливается, что обусловлено необходимостью быстрого освоения и унификации мирового опыта промышленного проектирования. Процесс формирования терминологии становится предметом отдельного изучения в архитектурной теории.

В статье рассматривается историческое формирование системы терминов в промышленной архитектуре - временные и географические границы появления и развития, транссрормация содержательной сути. Этот исторический контекст крайне важен для понимания процесса создания и развития базисных терминов и в конечном итоге - всей терминологии как системы, вербально закрепляющей инструменты ориентации и действия в конкретной области знаний.

Ключевые слова: термины, понятия, терминология, промышленная архитектура.

\section{INDUSTRIAL ARCHITECTURE TERMINOLOGY: FORMATION AND DEVELOPMENT}

Abstract

\section{Y. B. Morozova}

Terms and notions system is a necessary scientific and practice apparatus of any human activity including industrial architecture. In modern world the role of terminology is increasing constantly because the world globalization and need of the unification the industrial construction experience. The process of the terminology formation becomes the special subject of study in architectural theory.

The article is about the historical creation of terms system in industrial architecture - time and territory limits of terms appearance and development, their content transformation. This researches is extremely important for the understanding of the basic terms formation process and, after all, the process of terminology system development as a verbal tool for orientation in any field of knowledge.

Keywords: terms, notions, terminology, industrial architecture.

\section{Введение}

Терминология является неотъемлемым атрибутом любой области знаний, именно терминология формирует необходимую базу для теории и практики, в большой степени определяя успешность их развития. В условиях глобализации процессов и явлений современного мира терминологический аппарат начинает играть все более значимую роль, поскольку он позволяет унифицировать, а следовательно, и освоить мировой опыт любого вида деятельности, в том числе и промышленного проектирования.

У терминов и понятий наряду с настоящим есть и свое прошлое, история становления, временные и географические границы появления и формирования. Этот исторический контекст крайне важен для понимания процесса создания и развития базисных терминов и в конечном итоге - всей терминологии как системы, вербально закрепляющей инструменты ориентации и действия в конкретной области знаний.

Свой исторический дискурс имеет и терминологический аппарат промышленной архитектуры.

\section{Основная часть. Формирование терминологии}

Промышленная архитектура как самостоятельная область зодчества выделилась сравнительно недавно, в начале XVIII в. Переход к новому способу производства - машинному - инициировал пересмотр требований, предъявляемых к производственному пространству (рисунок 1).

Если ранее производственные постройки, несмотря на учет габаритов и условий функционирования отдельных механизмов, проектировались с ориентацией прежде всего на человека-работника, он был главным действующим лицом процесса, то с введением нового способа производства требования к пространству стали выдвигать машины, станки, способы их расстановки, подведения энергии и эксплуатации. Поэтому и первыми промышленными зданиями стали сразу многоэтажные корпуса, а не одноэтажные строения, с которых началась когда-то вся архитектура (рисунок 2).

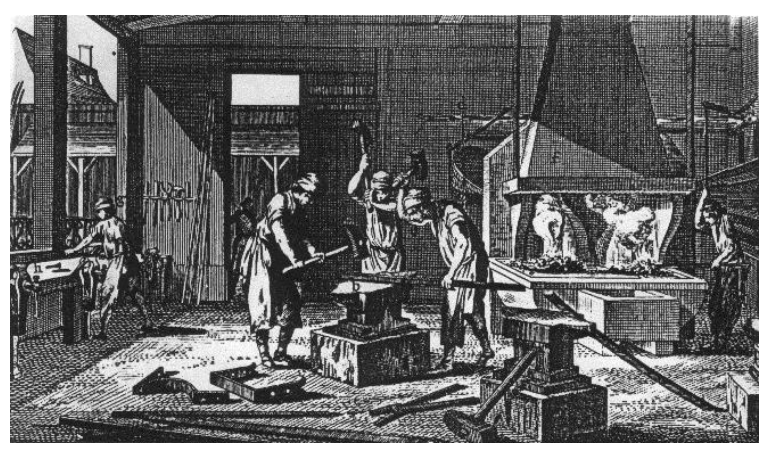

Рисунок 1 - Производственное пространство в доиндустриальный период (гравюра XVIII в.)

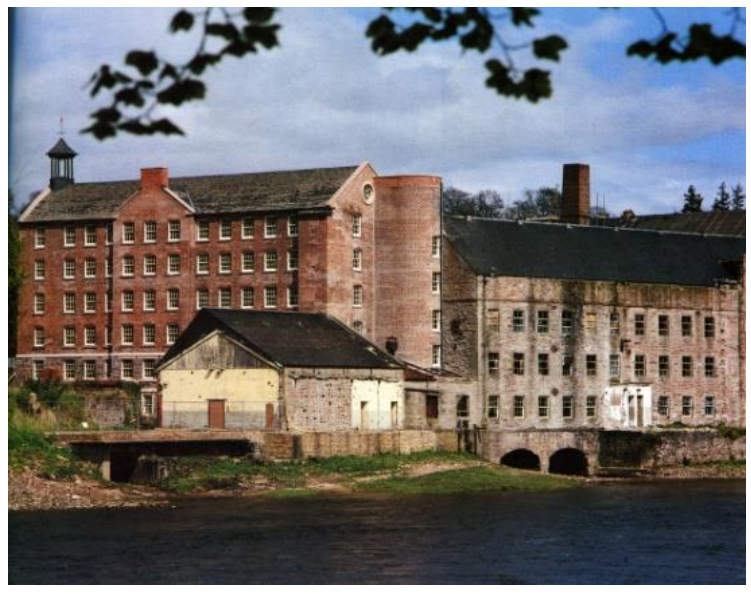

Рисунок 2 - Первые промышленные здания, Великобритания 
Вестник Брестского государственного технического университета. 2021

Четырех-пятиэтажные промышленные здания размещали станки на своих этажах из-за вертикальной системы передачи энергии, такое подведение было наиболее эффрективным, система действовала и давала возможность подключать десятки тысяч станков, вместо нескольких сотен в старых мануффактурах. Эта система передачи энергии (энергии воды, позднее - пара) основывалась на металлических стержнях - шафтах (shaf), она так и называлась «шафтовой» и могла успешно работать вертикально вплоть до восьмого ярусаэтажа (рисунок 3,4$)$.

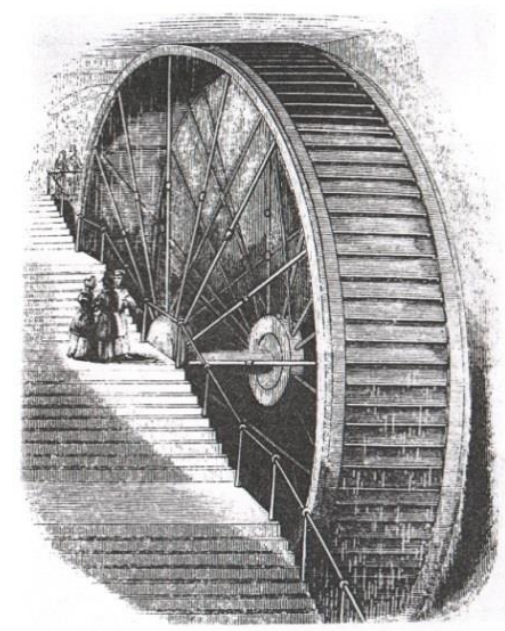

Рисунок 3 - Водяное колесо (гравюра XIX в.)

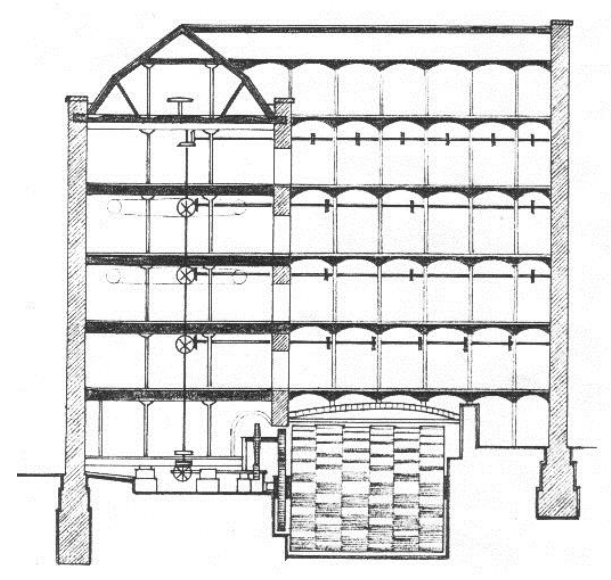

Рисунок 4 - Шафтовая система подведения энергии к станкам

Горизонтально же ее действие простиралось только на 30 м. Поэтому, пока не изобрели другую систему передачи энергии веревочную (wire-rope), одноэтажное строительство промышленных зданий было очень ограниченным, и многоэтажный корпус оставался приоритетным вплоть до середины XIX в. Сегодня одноэтажные здания составляют 70-80 \% мировой промышленной практики, однако технические возможности их возведения и эксплуатации стали доступны сравнительно недавно, в том числе и благодаря переходу на электрическую энергию.

Таким образом, главной особенностью промышленной архитектуры явилась ориентация одновременно на две системы - человека и машины, и последняя до сих пор в ряде производств продолжает диктовать основные требования к организации пространства Это кардинальное отличие промышленной архитектуры от гражданской буквально с первых дней оказало влияние на формирование терминов - выделилось два подхода: первый - производственный или функциональный, в соответствии с которым термин создавался по назначению протекающего в объекте процесса, и второй пространственный, или архитектурно-строительный, в основе которого лежали объемно-планировочные критерии объекта, без учета функциональной сути наполняемых его процессов. Оба подхода использовались до начала XX в.

Изначально наибольшее распространение получил производственный подход, он превалировал в XVIII - первой половине XIX вB. В англоязычной и отечественной практике промышленные предприятия и здания назывались по процессу, протекавшему в них: foundry плавильня, forge (smithy) - кузница, brewery - пивоварня, pottery гончарня и проч. В такой терминологии было много специфических инженерных и технологических десиниций, поэтому к концу XIX в. разнообразие процессов и обнаружившаяся потребность в унификации пространства для них обусловили отказ от производственного подхода. Он практически перестал существовать, сохраняясь в некоторых отдельных, специфических названиях, например в русскоязычной практике и сегодня используется термин «типография».

Второй пространственный подход охватил формирование двух групп терминов: определяющих объем, т. е. здание, и идентифицирующих территорию с группой зданий, т. е. предприятие. Первым стал введенный во Франции в 1771 г. и в Великобритании в 1796-1797 гг. термин «manufacture-manuffatorie-manufactory» - здание для производственного процесса [1]. Позднее, в 1803 г. появился близкий ему термин «factory», имевший английское происхождение $[1,2]$. В соответствии со словарем «Noah Webster's Dictionary», изданным в 1839 г., этот термин рассматривался как сокращенный от таnиfactory, устранение приставки manu- утверждало переход от ручного, мануального к механизированному труду, сам термин трактовался как пространство для «процесса переработки сырья в необходимые для использования продукты с помощью рук, механизмов или искусства» [3, с. 3-8].

Тем не менее, существует еще одна версия происхождения данного термина. Английский историк архитектуры Н. Певзнер предположил, что термин «factory» произошел от названия коммерческого агента (factor), такие агенты работали в складских зданиях товарных станциях, где хранилась, подвергалась первичной обработке, расфрасовывалась и продавалась оптом продукция, прибывавшая в морские порты-доки. Складские здания, как и производственные, строились многоэтажными и представляли одну из разновидностей первых промышленных объектов [1, с. 273]. Термины «manufactory» и "factory» некоторое время (до первой трети XIX в.) использовались одновременно в западноевропейских странах и США.

В русскоязычной практике заимствованный термин «мануфактура», напротив, применялся не к зданию, а к их группе - предприятию. А термин «фрабрика», сопоставимый с термином «factory», стал использоваться в России в конце XVIII в. и означал также, как и в Европе, отдельный цех, корпус, здание, где проводилась одна технологическая операция [4].

Термины «manufactory» и «factory» во второй половине XIX в. перестали использоваться для обозначения производственного здания, их заменили новые определения «workshop», и «shop». Причем термин «shop» в Европе ассоциировался с местом, где производят и продают, в США - с местом, где только производят [3, с. 61]. В то же время термин «factory» не исчез из употребления, но поменял свое содержание, теперь он обозначал не здание, а их группу предприятие. Допускалось применение данного термина к одному зданию, если не акцентировалась его форма или прочие пространственные аспекты. В 1914 г. фабричное законодательство США определило термин «factory» как место, где продукты и изделия производились, обрабатывались, ремонтировались, сортировались [3, с. 3-8]. Показательно, что такое же изменение содержательной сути термина произошло примерно в то же время и в России, здесь термин «фрабрика» стал употребляться в значении «целое предприятие», а не «здание, корпус». Это является одним из примеров иллюстрации глобальной общности процесса развития промышленной архитектуры, одинаковости механизмов этого развития для разных стран и регионов [5].

B XX в. определяющим при формировании терминов в промышленном проектировании становится пространственный подход. Этого требовала постоянно расширяющаяся номенклатура технологических 
Вестник Брестского государственного технического университета. 2021

процессов, где унификация, поиск общего, универсального при формировании производственного пространства являлись единственным средством сдержать в управляемых рамках процесс наращивания многообразия архитектурных типов. Производственные здания начинают определять более универсальными терминами, не отражающими назначения протекающих в них процессов: «цех», "корпус» industrial structure, industrial building; production shed (термин введен во второй половине XX в. Р. Бэнемом), piched-roof, loft - «шедовый корпус», «павильонное здание» и др.; предприятие, завод - works, plant $[3,6,7]$.

Термин «works» появился в начале XIX в., он пришел из практики гражданского строительства Великобритании, где его использовали первоначально при строительстве фортификационных сооружений, позднее - доков и мостов. Термин «plant» сложился в 1880 г. в США для определения предприятия, он относительно быстро распространился и в Европе, где начал вытеснять термин «Works», последний не исчез полностью, но стал менее употребляемым. Оба термина «works» и «plant» применялись для обозначения сложных, многообъектных производств, таких как металлургические и машиностроительные предприятия, за исключением текстильных, для которых довольно долго использовался термин «mill» [3].

Слово «mill» в переводе означает молоть, вращать, и поскольку первыми фабричными корпусами были английские прядильные фабрики, станки которых приводились в действие энергией водь путем вращения колеса или их системы, термин «тіll» прочно закрепился за текстильными предприятиями. Пришедшая на смену в конце XVIII в. паровая энергия передавалась все тем же шафтовым способом, что продлило срок жизни термина «тіll» для предприятий и зданий этой отраслевой направленности. Но в конце XIX в. термин «mill» полностью исчез из употребления, и любые предприятия начали называть works, plant, factory.

В русскоязычной практике для обозначения предприятия уже в конце XVIII в. стал использоваться термин «завод», он имел оригинальное происхождение, не представлял заимствования, как в случае с термином «мануфактура», и не демонстрировал в отличие от западноевропейской и американской практики распространенный В то время производственный принцип формирования дефиниций. Во второй половине XIX в. к нему добавился термин "фабрика» в результате смены содержания этого понятия, как было отмечено выше. Обычно использование термина «фрабрика» распространялось на предприятия так называемой сегодня легкой промышленности, например, Добрушская бумажная фабрика, ткацкая фрабрика братьев Варгуниных. Для предприятий пищевой промышленности применялись как первый, так и второй термины - Парецкий рафинадный завод, пивоваренный завод братьев Леккерт, конфетная фабрика Бабаева, Гродненская табачная фабрика и прочие, объекты добывающей, машиностроительной, металлообрабатывающей отраслей идентифицировались только с использованием термина «завод».

Система терминов, определяющих сегодня промышленную типологию объемных и территориальных объектов, основывается на пространственном, архитектурно-строительном подходе, однако использование производственного подхода может иметь место при идентификации территориальных объектов, например предприятий, к общеупотребляемым терминам «фрабрика», «завод», «plant», «works» добавляется функциональная характеристика производства: «трикотажная фабрика», «литейный завод», «механический чех», "сборочный корпус», "fast food factory», "car plant», "print works», «assembly industrial building».

В 1950 г. стала формироваться группа терминов, определяющих систему человека в промышленном производстве. Это было обусловлено потребностью общества в обеспечении достойных условий труда путем развития сферы обслуживания рабочих. Многообразие видов обслуживания обусловило достаточно разнообразную терминологию этих объектов в научной, методической и нормативной литературе, так, например, в отечественной практике до сих пор используются термины: «вспомогательные здания», «вспомогательные помещения промышленных предприятий», "общественные объекты», «социально-бытовые объекты», «культурно-бытовые объекты», «административно-бытовые объекты» и т. д. Англоязычный термин «social service objects» представляется наиболее приемлемым определением рассматриваемых объектов, без конкретизации вида обслуживания и группы работающих.

Объекты промышленной архитектуры, как уже отмечалось, охватывают два пространственных уровня - это здания и сооружения (объемные объекты) и застроенные промышленными зданиями площадки разного размера и способов пространственной организации (территориальные объекты). Терминология территориальных объектов первоначально касалась только предприятия и промышленного поселения. Процесс формирования первого понятия уже приведен выше, что же касается промышленного поселения, то его формы, несмотря на общие процессы развития, все же существенно отличались в странах и регионах, в связи с чем складывались очень специфичные термины - «industrial settlement», «industrial village», «company town», «город-завод», «промышленная деревня», «рабочий поселок», «соцгород» и проч. По смысловому значению сопоставимыми здесь можно считать термины «город-завод» и «сотрапу town», как территориальные объединения объектов проживания и производства. Первый термин введен в научную практику А. В. Луначарским в 1920 г. вместо ранее использовавшегося термина «горный город». Второй термин появился в американской практике в конце XIX в. и заменил сравнительно редко используемое более раннее название «mill town». Сходными с этими терминами являются шведский термин «bruck» и французский «cite ouvriere» [8]. Сегодня типологическая единица промышленного поселения уже ушла в прошлое, поскольку строительство этих объектов полностью прекратилось во второй половине XXв., соответственно не столь актуальным является вопрос их современной типологии и координации [5].

Однако возникновение новых градостроительных образований промышленного профиля в начале $\mathrm{XX}$ в. и их продолжающееся развитие обусловили создание разветвленной системы терминов для этих территориальных объектов : «промышленный узел», «промышленный район», «промышленно-селитебный район», «промышленноселитебный комплекс», «промышленно-коммунальный район», «промышленная зона», «industrial tract», «industrial subdivision», «industrial clusters», «industrial estate», «industrial district», «industrial park», «industrial zone», «techno-park». Дифференциация этих определений в отечественной практике связана со степенью концентрации и кооперации производства, в зарубежной практике дифференциация основывается на степени единого и заранее предусмотренного решения планировочных вопросов. Наиболее схожими здесь являются термины «промышленный район», «промышленный узел»«industrial estate», «industrial district», «trading estate». В отечественной и зарубежной специальной литературе нередко встречается использование нескольких терминов с одним смысловым значением (например, «промышленный район» - «промышленный узел» «промышленная зона», «industrial estate» - «industrial district») [9].

И в завершение следует остановиться на термине «промышленная архитектура», объединяющем объекты материальной среды, создаваемые человеком для осуществления производственных процессов. При этом объекты предназначаются не для всех производственных процессов, а только для промышленных, отличительными характеристиками которых являются широкое использование машин и механизмов, серийность и массовость процесса, разделение его на операции и закрепление за ними рабочих, вовлечение их в производство по тем же принципам, что и машин. Поэтому понятие «промышленная архитектура» является более узким, чем понятие «архитектура производственных объектов». Последнее включает все объекты для трудовых процессов, имеющих целью создание материального продукта.

Термин «промышленная архитектура» в русскоязычной практике появился в начале XX в. В 1915 г. А. Степанов в журнале «Зодчий» опубликовал статью, где было использовано словосочетание «промышленное зодчество», а в 1929 г. вышла статья И. Николаева, название которой «Промышленная архитектура» уже вводило данный термин в научно-практический оборот. После этого использовавшиеся в России с 1870 г. тождественные термины «заводская 
архитектура», «фрабрично-заводская архитектура» исчезли из употребления [10]. Термины "утилитарная архитектура» и «рациональная архитектура», продолжавшие существовать в теоретических работах, не отождествлялись полностью с термином «промышленная архитектура», поскольку охватывали только художественные, стилистические аспекты [11, с. 29]. В западноевропейской практике термин «industrial architecture», тождественный русскоязычному, сформировался в конце XIX в. в Германии («die industriale arkitektur»), ранее в европейской практике употреблялись термины «architecture for industry» и "architecture for the work». В настоящее время в США наряду с «industrial architecture» распространился термин «сотmercial architecture». Он является более широким, поскольку включает не только предприятия, но и объекты торговли и деловой активности - магазины, выставочные центры и т. д. [12], что свидетельствует о постоянно идущем процессе типологических трансфрормаций в архитектуре.

\section{Заключение}

Терминологический аппарат промышленной архитектуры как самостоятельной области зодчества формировался на протяжении трехсот лет. Этот процесс шел одинаково в разных странах, причем имели место как заимствования термина, его перевод, так и создание собственного, но по тем же принципам (например таких терминов, как «manufacture-manuffatorie-manufactory-мануфрактура», "factoryфабрика», «plant-works-завод»). Однотипные термины в отечественной и зарубежной практике меняли одновременно свою содержательную сущность. Так, термин «factory-фрабрика» во второй половине XIX в. в США, европейских странах и России стал обозначать не отдельное здание, а предприятие. Практически в одно и то же время менялся и принцип формирования терминов - от производственного или функционального, предполагающего создание термина по назначению протекающего в объекте процесса, к пространственному или архитектурно-строительному, складывающемуся на основе объемно-планировочных характеристик объекта, без функциональной определенности наполняемых его процессов. Используемая в настоящее время в отечественной и зарубежной практике система терминов отражает единый исторический процесс их создания и демонстрирует общие подходы к их сегодняшнему формулированию и употреблению.

\section{Список цитированных источников:}

1. Pevsner, N. A history of building types / N. Pevsner. - London: Thames and Hudson, 1976. - $352 \mathrm{p}$.

2. Skempton, A. W. Evolution of the steel frame building / A. W. Skempton // Guilds Engineer. - 1959. - \# X. - P. 37-51.

3. Bradley, B. H. The Works: the industrial architecture of the United States / B. H. Bradley. - NY, Oxford: Oxford University Press, 1999. $347 p$.

4. Лотарева, Р. М. Города-заводы России: XVIII - первая половина XIX века / Р. М. Лотарева. - Екатеринбург : Изд-во Урал. ун-та, 1993. -216 c.

5. Морозова, Е. Б. Эволюция промышленной архитектуры / Е. Б. Морозова. - Минск : БНТУ, 2006. - 240 c.

6. Richards, C. Multi-story buildings for industry and trade / C. Richards // Industrial buildings: a design manual / J. Adam, K. Hausmann, F. Juttner; transl. F. Greenwood; edit. by Ch. Rochow. - Basel: Birkhauser, 2004. - P. 27-29.

7. Banham, R. A concrete Atlantis: U.S. industrial buildings and European modern architecture, 1900-1925 / R. Banham. - Cambridge, Mass.: MIT Press, 1986. -266 p.
8. Garner, J. S. The company town: architecture and society in the early industrial age / J. S. Garner. - NY, Oxford: Oxford University Press, 1992. $-245 p$.

9. Bredo, W. Industrial estates: tool for industrialization / W. Bredo. Glencoe, Illinois: The Free Press, 1960 - 240 p.

10. Фишер, В. А. Краткое руководство к специальной архитектуре и инженерному делу. Для помощников архитекторов и инженеров. Согласно программы, утвержденной МПС для испытания техников, с дополнительными сведениями по архитектуре и инженерному делу: атлас / В. А. Фишер. - СПб. : Издание К. Л. Риккера, 1898. - 639 таблиц.

11. Красовский, А. К. Гражданская архитектура. Части зданий / Соч. Апполинария Красовского, проф. гражд. архитектуры в Ин-те Корпуса инженеров путей сообщ. и в Строит. училище Гл. упр. путей сообщ. и публич. зданий; С атласом черт. на 102 л. - СПб. : В типогр. Воен.-учеб. заведений, 1851. - 579 с.

12. Commercial building design integrating climate, comfort and cost / compos. by Van Nostrand Reinhold Company. - NY, 1987. - 236 p.

\section{References}

1. Pevsner, N. A history of building types / N. Pevsner. - London: Thames and Hudson, 1976. - 352 p.

2. Skempton, A. W. Evolution of the steel frame building / A. W. Skempton // Guilds Engineer. - 1959. - \# X. - P. 37-51.

3. Bradley, B. H. The Works: the industrial architecture of the United States / B. H. Bradley. - NY, Oxford: Oxford University Press, 1999. $347 \mathrm{p}$.

4. Lotareva, R. M. Goroda-zavody Rossii: XVIII - pervaya poloviny XIX veka / R. M. Lotareva. - Ekaterinburg : Izd-vo Ural. un-ta, 1993. $216 \mathrm{~s}$.

5. Morozova, E. B. Evolyuciya promyshlennoj arhitektury / E. B. Morozova. - Minsk : BNTU, 2006. - 240 s.

6. Richards, C. Multi-story buildings for industry and trade / C. Richards // Industrial buildings: a design manual / J. Adam, K. Hausmann, F. Juttner; transl. F. Greenwood; edit. by Ch. Rochow. - Basel: Birkhauser, 2004. - P. 27-29.

7. Banham, R. A concrete Atlantis: U.S. industrial buildings and European modern architecture, 1900-1925 / R. Banham-Cambridge, Mass.: MIT Press, 1986. $-266 \mathrm{p}$.

8. Garner, J. S. The company town: architecture and society in the early industrial age / J. S. Garner. - NY, Oxford: Oxford University Press, 1992. $-245 \mathrm{p}$.

9. Bredo, W. Industrial estates: tool for industrialization / W. Bredo. Glencoe, Illinois: The Free Press, 1960. - 240 p.

10. Fisher, V. A. Kratkoe rukovodstvo $k$ special'noj arhitekture i inzhenernomu delu. Dlya pomoshchnikov arhitektorov i inzhenerov. Soglasno programmy, utverzhdennoj MPS dlya ispytaniya tekhnikov, s dopolnitel'nymi svedeniyami po arhitekture i inzhenernomu delu: atlas / V. A. Fisher. - SPb. : Izdanie K. L. Rikkera, 1898. - 639 tablic.

11. Krasovskij, A. K. Grazhdanskaya arhitektura. CHasti zdanij / Soch. Appolinariya Krasovskogo, prof. grazhd. arhitektury v In-te Korpusa inzhenerov putej soobshch. i v Stroit. uchilishche Gl. upr. putej soobshch. i publich. zdanij; S atlasom chert. na 102 I. - SPb. : V tipogr. Voen.-ucheb. zavedenij, 1851. $-579 \mathrm{~s}$.

12. Commercial building design integrating climate, comfort and cost $/$ compos. by Van Nostrand Reinhold Company. - NY, 1987. - 236 p.

Материал поступил в редакцию 11.03.2021 